$2013 / 2$

\title{
Active Battery Balancing for Battery Packs
}

\author{
Javier Gallardo-Lozano ( $P h D$ student, University of Extremadura - UE), \\ Abdul Lateef (PhD student, McMaster University), Enrique Romero-Cadaval (Professor, UE), \\ M. Isabel Milanés-Montero (Professor, UE)
}

\begin{abstract}
In electric vehicle applications, it is necessary to use series strings of batteries since the required voltage is higher than the one that can be obtained from a single battery. Due to several factors, imbalance of batteries in these battery systems is usual and an important factor that has to be taken into account. Many balancing methods have been developed with a lot of different advantages, but all of them also have a lot of disadvantages such as complexity and/or high cost, which are the common problems that can be found in most of these equalization methods. In the present work, a low cost and very simple equalization method is proposed, in which a novel control is applied to a shunting transistor topology. It allows the transistors to regulate the amount of current that goes through each battery cell in the string depending on their State of Charge (SOC), during the charging process. This control ensures that the least charged cells to be charged faster, and the most charged ones to be charged more slowly. Design criteria are discussed and simulation results are carried out in a generic battery low power application which proves the control method. Fast equalization with a low complexity and cost is obtained.
\end{abstract}

Keywords - Batteries, current control, power MOSFET, power dissipation.

\section{INTRODUCTION}

Along the last years, the research on electric vehicles has become of special interest for many reasons such as environmental awareness (which leads us to a more efficient transportation vehicles and Government incentives), continuous increase of the oil price due to the natural resource exhaustion and the instability in the Middle East, etc. Hybrid electric vehicles (HEVs) were the first proposed solution to the trend toward more electric vehicles [1], and nowadays BEVs (Battery Electric Vehicles) are coming out more and more. Different battery technologies have been studied and utilized for the EVs (Electric Vehicles), but new researches are developing the Lithium-ion batteries which are becoming the most viable option for portable and mobile energy storage applications, especially for EVs [2]-[4].

Most of applications for batteries need higher voltage than can be obtained from a single electrochemical battery and series strings of cells (each battery that makes up the whole battery pack is called cell hereafter unless otherwise noted) are used to meet voltage requirements in EVs [5]-[6].

Imbalance of cells in battery systems is very usual and an important matter in the battery system life. A battery system without a balancing technique can lead its cells to be overcharged, undercharged, or even overdischarged, and it takes special importance in Li-ion cells [7]-[9]. The reasons of this imbalance may be of two categories [10]: internal sources (manufacturing variance in physical volume, internal impedance and self-discharge rate) and external sources such as thermal difference across the pack.

There are many different balancing methods [11]-[13]. Balancing methods can be classified into passive balancing methods and active balancing ones. In passive equalization an external overcharge is enforced to allow weak cells to reach the less weak ones. At high SOC (Battery State-of-Charge), the charge process for lead-acid and nickel cells becomes inefficient since its water begins to dissociate and energy goes into electrolysis rather than the charge process. However, Liion cells do not have the aqueous component, and so do not have the gassing overcharge process that allows a passive equalization in other chemistries. Since the Li-ion battery is the most important one, according to these previous lines, this paper is focused on an active balancing method. The different active methods are summarized in Table I [11]-[12].

TABLE I

ClassificAtion of ACtive Balancing Methods

\begin{tabular}{|c|c|c|c|}
\hline & Shunting Method & Shuttling Method & Energy Converter Method \\
\hline & Complete shunting & & \\
\hline Resistor Balancing & Dissipative resistor & & \\
\hline Capacitor Balancing & & $\begin{array}{l}\text { - Single switched capacitor } \\
\text { - Switched capacitor } \\
\text { - Double-tiered capacitor }\end{array}$ & \\
\hline Inductor Balancing & $\begin{array}{l}\text { - Single inductor } \\
\text { - Multi-inductor } \\
\text { - Boost shunting }\end{array}$ & & $\begin{array}{l}\text { - Single-windings transformer } \\
\text { - Multi-windings transformer } \\
\text { - Multiple-windings transformer }\end{array}$ \\
\hline Energy Converter Balancing & & & $\begin{array}{l}\text { - Cûk converter } \\
\text { - Buck or/and Boost converter } \\
\text { - Flyback converter } \\
\text { - Ramp converter } \\
\text { - Full-bridge converter } \\
\text { - Resonant converter } \\
\text { - Quasi-resonant converter }\end{array}$ \\
\hline
\end{tabular}


Shunting active balancing methods remove the excess energy from the higher voltage cell (or cells) with the aim to let them wait for the lower voltage cell (or cells) to catch up with them.

Shuttling active balancing methods utilize external energy storage devices (usually capacitors) to shuttle the energy among cells in order to balance them.

Energy converters are featured by fully control of balancing process.

All of these balancing methods have been developed with a lot of advantages, but all of them also have a lot of disadvantages such as complexity and/or high cost, which are some of the common features that can be found in most of these equalization methods. In the present work a low cost and very simple method is proposed, presenting a novel control for a shunting transistor balancing method in a generic battery charging process. In Section II the proposed equalization system is presented and in Section III the different simulation results are shown, validating this proposed control balancing method. Finally, Section IV remarks the different conclusions.

\section{II.EQUALIZATION SYSTEM DESIGN}

The main idea of this equalization system is to use a MOSFET working in saturation mode as a variable resistance, instead of using a resistance, whose value is fixed. The aim of this new control is to regulate the amount of current that goes through the cells that make up the battery in order to balance the whole battery system. A large number of advantages are obtained by using this equalization system together with the novel control. In addition to the advantages of the shunt resistor -for example reliability, effectiveness, low cost, simple to implement, suitability in modular design, fast equalization during charging, etc.- it reduces disadvantages such as energy losses, since the bypassed current through the MOSFET decreases when its corresponding cell is being closer to be balanced or even it stops being bypassed under some conditions.

The bypassed current through the MOSFET is regulated varying its gate-source voltage according to Fig.1.

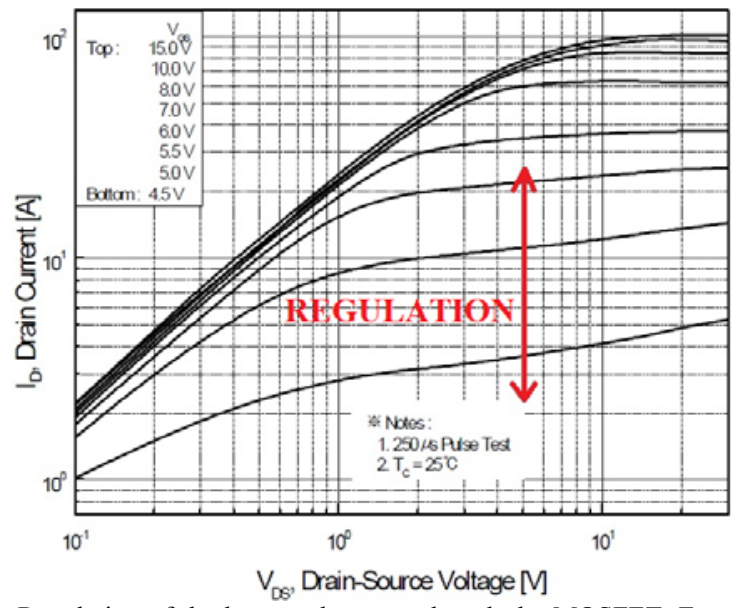

Fig.1. Regulation of the bypassed current though the MOSFET. Example of the SiS452DN MOSFET curve.

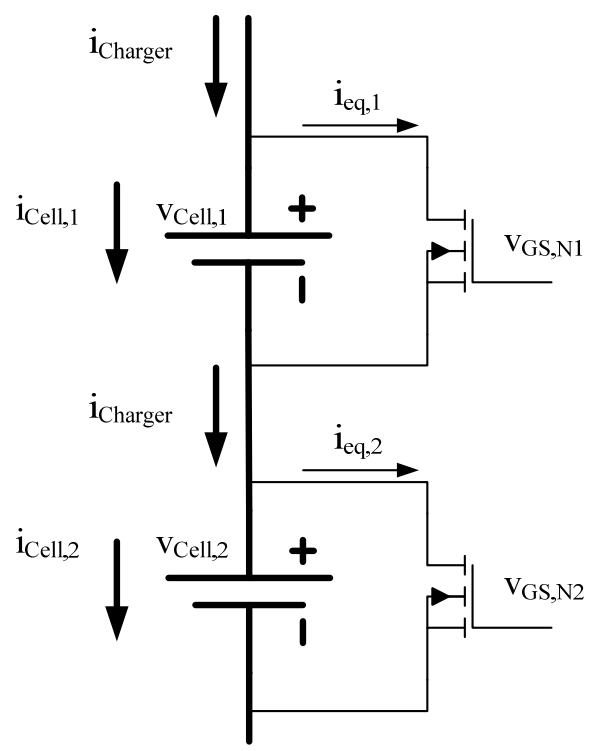

Fig.2. Configuration of the equalization system for two cells. Distribution of the currents in battery charging mode.

The higher the gate-source voltage of the MOSFET is, the higher the bypassed current through the MOSFET is, and therefore the less the corresponding cell is charged, and vice versa.

In order to be able to equalize during the charging process or during the regenerative braking, a MOSFET is set in parallel to each cell of the string. The MOSFET is an $n$ channel device. The topology is shown in Fig.2.

The main idea of the equalizer is to measure the voltage of every cell that makes up the battery, set the average voltage of the aforementioned measurements which is considered the reference one, and extract the difference between every cell voltage and the cells average value.

During the battery charging process, cells with lower voltage than the average one need to be charged as much as possible in order to reach the average value as soon as they can. These cells receive all the current that comes to the battery from the charger, and therefore their corresponding MOSFETs (n-channel one) are set to the off-state and they do not bypass the cell. On the other hand, cells with higher voltage than the average one need to stop being charged, in order to approximate to the average value more and more since this mentioned average value is increasing as the lower voltage cells are being charged. Once all the cells reach the reference the battery can be considered balanced.

With the aim to optimize the charging process, instead of bypassing all of the current of the higher voltage cells until the battery is balanced and then keeping charging all the cells together, the higher voltage cells are charged in a lower rate of current, bypassing the remaining current. The closer to the average value the higher cell voltage is, the lower the amount of current is bypassed by the corresponding MOSFET. Once the cell voltage reaches the average one, the MOSFET is set to the off-state and all of the current that comes to the battery goes through the cell. It allows the system to decrease the energy losses. 


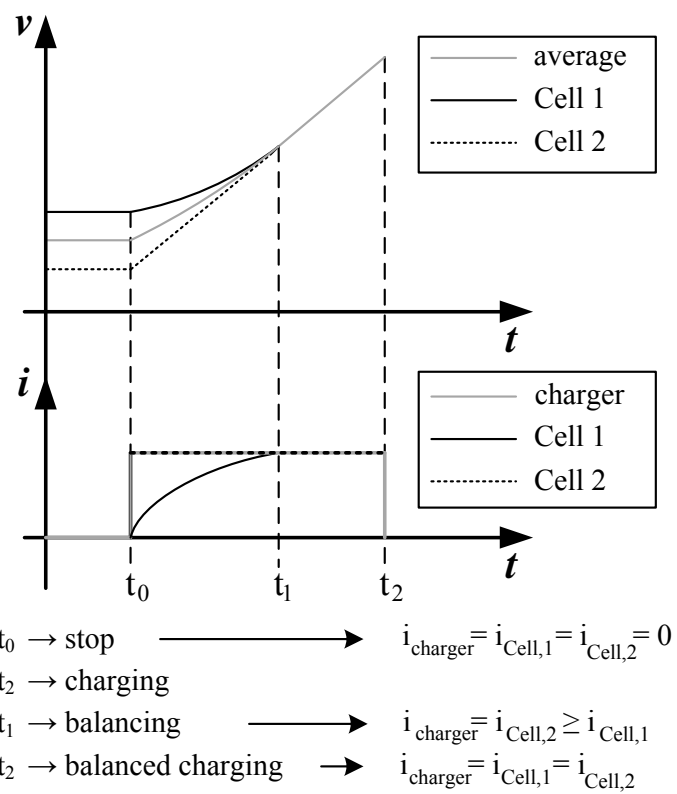

Fig.3. Schematic of the batteries and average voltages in an a) unbalance system. b) charging equalization process.

The aforementioned process of equalizing under the charge conditions is depicted in Fig.3.

In order to decide how much current is bypassed when a cell is unbalanced, a maximum difference $\operatorname{diff}_{\max }$ between the cell voltage and the reference (the average value) is set. The difference of the $i$-cell diff $_{i}$ is defined as

$$
\operatorname{diff}_{i}=V_{b a t_{i}}-\bar{V}_{b a t}
$$

where:

$V_{b a t_{i}}$ is the voltage of the battery (cell) number $i$ and

$\bar{V}_{b a t}$ is the average voltage of the whole battery system, obtained as

$$
\bar{V}_{b a t}=\frac{1}{N} \sum_{i=1}^{N} V_{b a t_{i}}
$$

where $N$ is the number of batteries connected in series that builds the whole battery system.

When the difference of an unbalanced cell is equal or higher than diff $f_{\text {max }}$, all of the current is bypassed through the corresponding MOSFET, and therefore the system is waiting for the cell voltage to approach to the average one. When the difference is equal or lower than diff $f_{\max }$, the current is partially bypassed to the cell, and the difference keeps decreasing, until the error (the difference between the cell voltage and the reference one) is zero, when all of the current must go through the cell, so the MOSFET is set to its off-state. As it has been mentioned and also shown in Fig.1, the amount of bypassed current is set by the gate-source voltage of the MOSFET (nchannel). According to the previous lines, the gate-source voltage is obtained as a linear function of the difference between the cell voltage and the average one. Fig.4 represents such relationship.

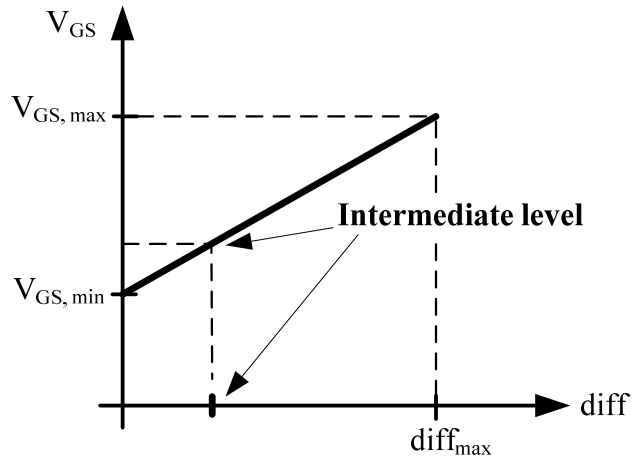

Fig.4. Linear relation between the gate-source MOSFET voltage and the difference between the cell voltage and its reference one.

For an n-channel MOSFET, the equation of the drain current in saturation mode is

$$
I_{D}=\frac{K}{2}\left(V_{G S}-V_{T}\right)^{2}\left(1+\lambda V_{D S}\right),
$$

where $I_{D}$ is the MOSFET current, $K$ is the conduction parameter, $V_{G S}$ is the gate-source voltage, $V_{T}$ is the threshold voltage, $\lambda$ is the lambda parameter and $V_{D S}$ is the drain-source voltage.

The MOSFET works in the saturation region whenever it is kept working fulfilling

$$
V_{G S} \geq V_{T}
$$

and

$$
V_{D S} \geq V_{G S}-V_{T} \Rightarrow V_{G S} \leq V_{D S}+V_{T} .
$$

According to (4), $V_{G S, \min }$ from Fig.4 is obtained as

$$
V_{G S, \min }=V_{T} .
$$

$V_{G S, \max }$ from Fig.4 is found from (3) according to

$$
V_{G S, \max }=\sqrt{\frac{2 I_{b a t, \max }}{K\left(1+\lambda V_{D S}\right)}}+V_{T} .
$$

The equation of the line in Fig.4, is obtained as

$$
\frac{V_{G S}-V_{G S, \text { min }}}{\text { diff }-0}=\frac{V_{G S, \text { max }}-V_{G S, \text { min }}}{\text { diff }_{\text {max }}-0},
$$

which leads to

$$
\frac{V_{G S}-V_{T}}{\text { diff }}=\frac{\left(\sqrt{\frac{2 I_{b a t, \max }}{K\left(1+\lambda V_{D S}\right)}}+V_{T}\right)-V_{T}}{\text { diff }_{\max }},
$$

and therefore

$$
V_{G S}=\frac{\sqrt{\frac{2 I_{b a t, \max }}{K\left(1+\lambda V_{D S}\right)}}}{\text { diff }_{\max }} \text { diff }+V_{T} .
$$


The lower the difference is, the lower the bypassed current is, and the less the equalization is being carried out. It means that the reference would be like an asymptote that is reached in the infinite time. Once the cell voltage is inside a very narrow margin of error (very small difference with the reference) the bypassed current is negligible, but before reaching this margin the speed of the equalization process was slower and slower, that increases the energy losses, and after having reached this cited margin, the system keeps equalizing until the infinite time that is when the reference is reached also decreasing the efficiency.

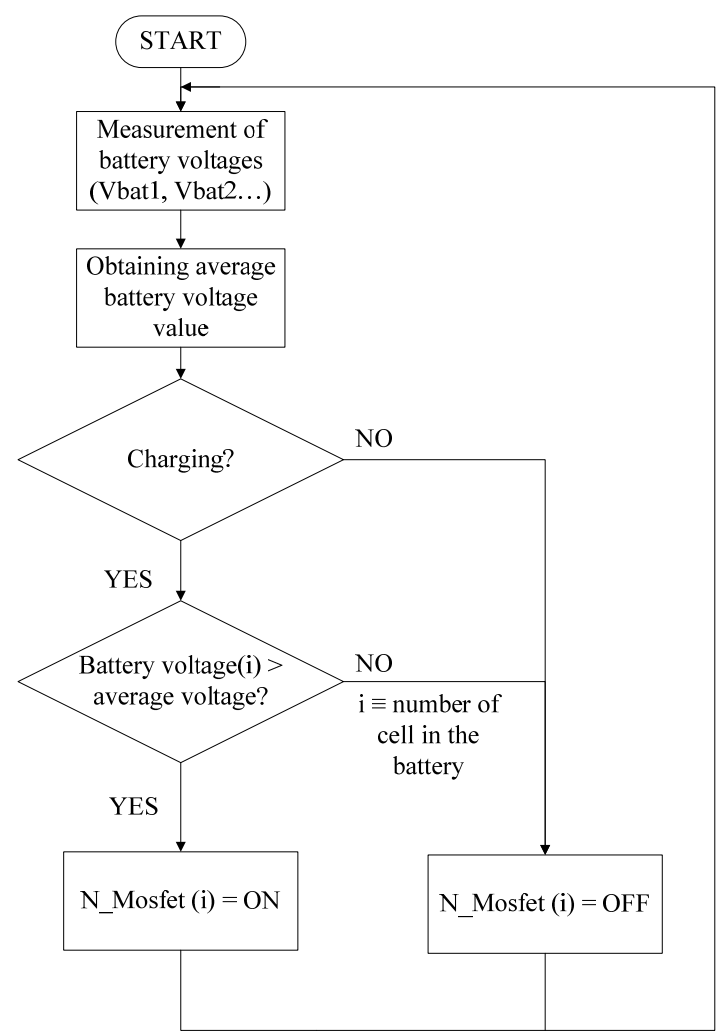

Fig.5. Algorithm of the activation/deactivation of the different MOSFETs.

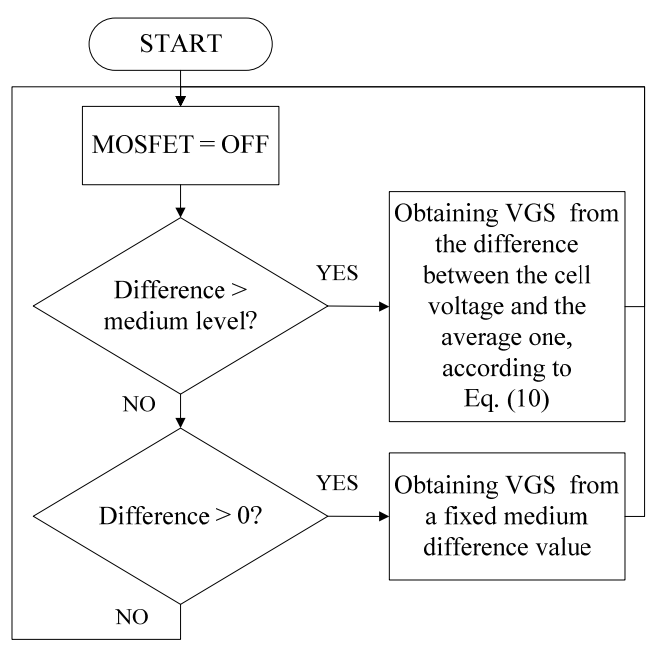

Fig.6. Algorithm explaining how to obtain the gate-source voltage of the activated MOSFETs.
In order to decrease the energy losses even more, and therefore optimize the control more, an intermediate level of $V_{G S}$ (and diff) is set. When an unbalanced cell starts the equalization process from a high difference, the control is kept according to Fig.4, but when the difference reaches the mentioned intermediate level, from that moment this difference is considered fixed (although it really keeps decreasing), and so the bypassed current is fixed into an intermediate value that allows the cell voltage to get zero error (zero difference between the cell and reference voltage).

Once the cell voltage comes to zero error, and its corresponding MOSFET is set to off-state, the cell equalization process is stopped. Considering that there can be manufacturing and thermal variances between cells, its voltage could be oscillating around the reference that could cause the activation and deactivation of the equalization process, and a considerable increase in the energy losses. The way this problem is solved consists of the utilization of the aforementioned intermediate difference level. When the cell voltage gets the zero error, the equalization process is deactivated until the difference comes to the intermediate level that is when the equalization is activated again. This idea avoids energy losses which can decrease the efficiency of the system. The algorithm that decides whether the n-channel MOSFET are activated or deactivated is shown in Fig.5. The algorithm that explains how the gate-source MOSFET voltage is calculated is shown in Fig.6.

\section{Simulation Results}

The modeled system consists of 3 cells, each of them in parallel to an n-channel MOSFET, the equalizer control system and finally the input of the whole system, which is the current that is injected into the whole battery system or delivered by this one. The cells utilized are the batteries "Batterist PQ5400 LP2", which have been modeled [14]-[15]. The n-MOSFETs (modeled in their saturation region) are the "Vishay Siliconix SiS452DN". The Matlab/Simulink model of the proposed system is given in Fig.7. Below the charging process is simulated and studied with a help of this model.

The amount of current that is injected into the battery is set to $7 \mathrm{~A}$. The SOC of the cells is set to $50 \%, 60 \%$ and $70 \%$ for the cell number 1 , the cell number 2 and the cell number 3 , respectively. Fig. 8 is divided into three subplots. The first subplot shows the cells voltages. It can be seen that after some hundreds of seconds, the system can be considered balanced. The second subplot shows the cells currents. Two of the cells (the ones which started with a SOC of $50 \%$ and $60 \%$ ) are being injected all the current since their voltage is lower than the average one. One of these cells with lower SOC suffers a small deviation that is solved placing its control in the intermediate level, and recovering the balanced state after a short time. The remaining cell (the one which started with a SOC of $70 \%$ ) is not injected current at the beginning, then it is injected more and more gradually, until it reaches a level (the intermediate level aforementioned) in which the amount of injected current keeps constant in an intermediate value, and finally the cell is injected all of the current $(7 \mathrm{~A})$. 

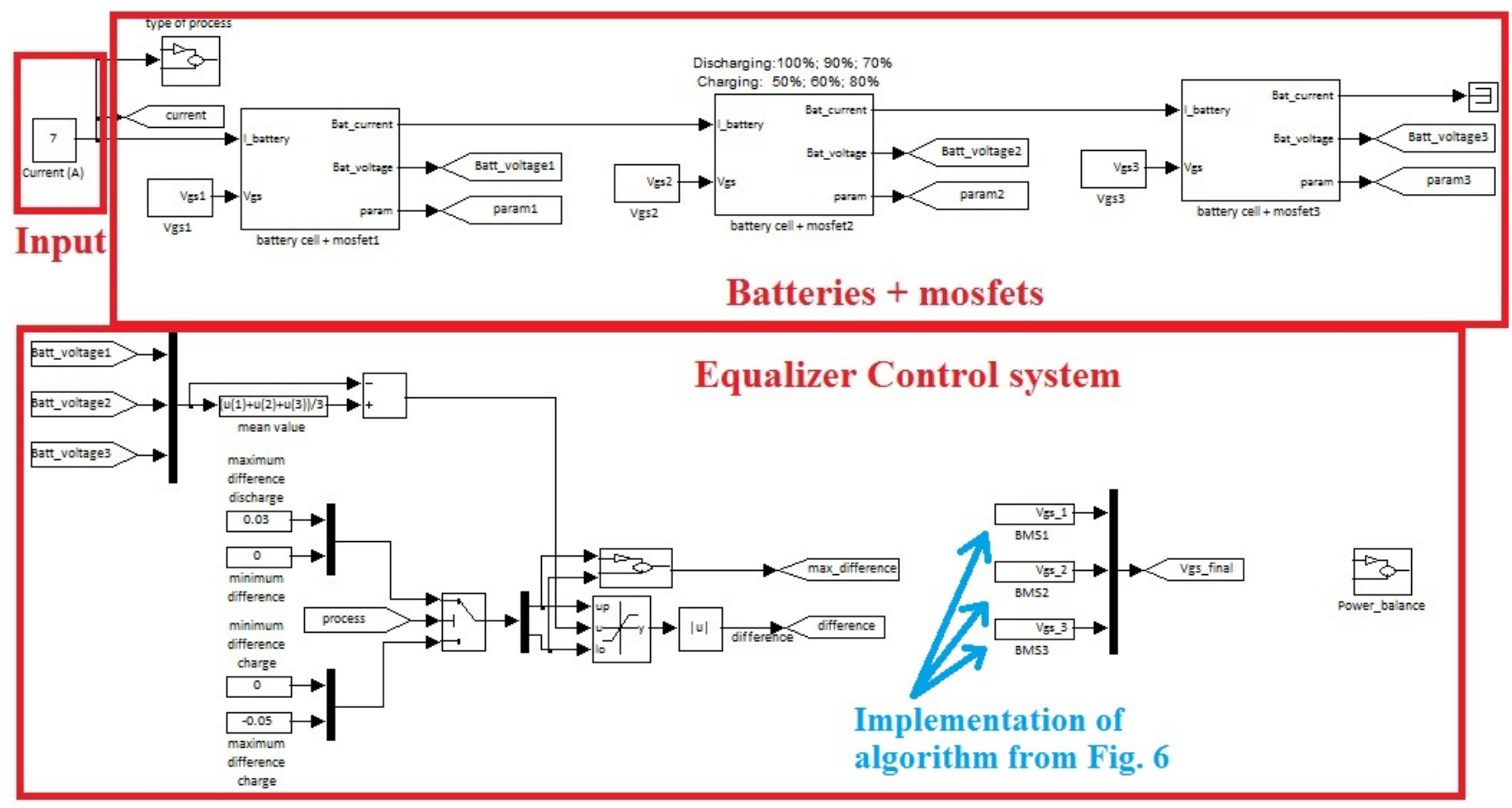

Fig.7. General block diagram of in Matlab/Simulink.
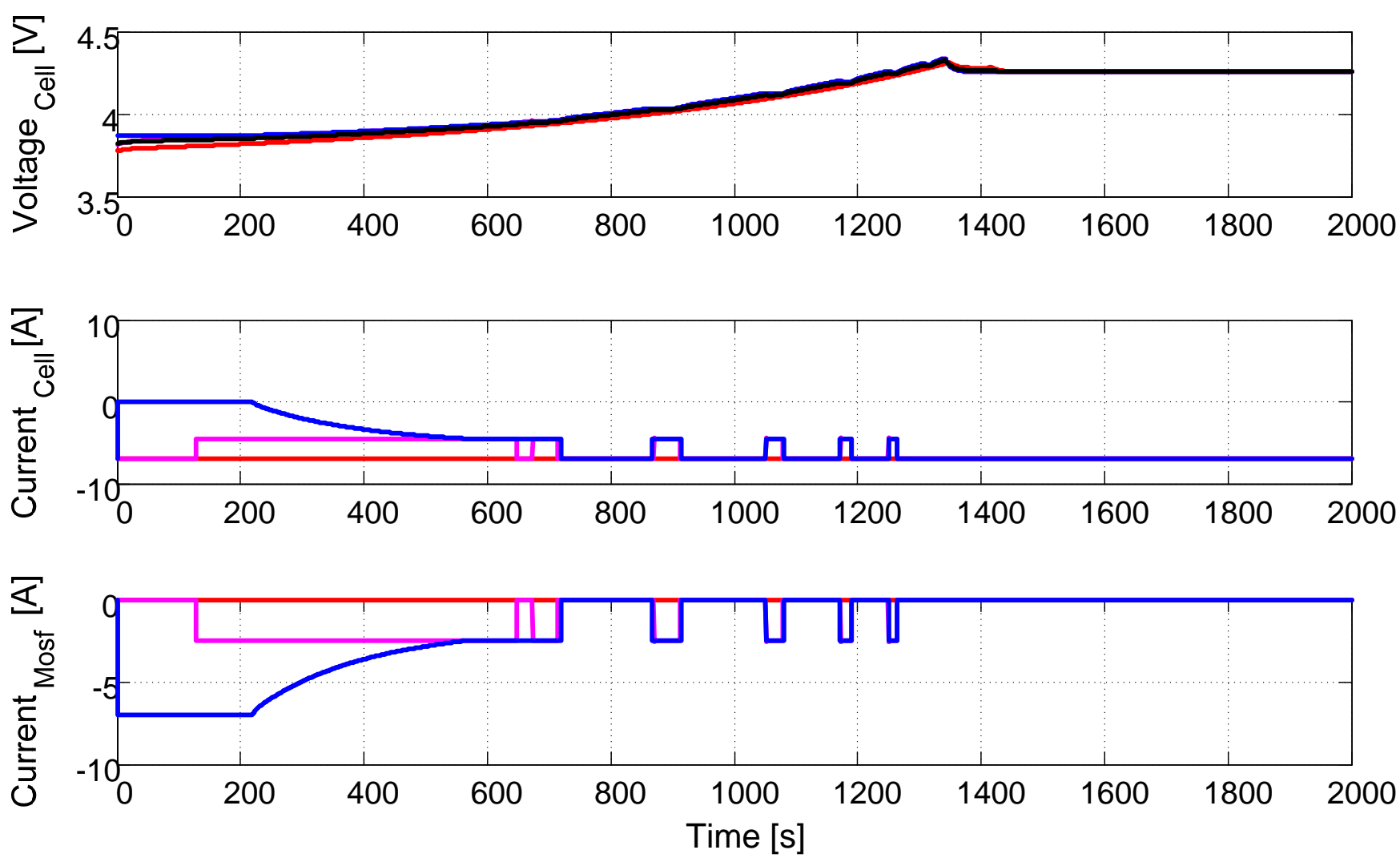

Fig.8. Matlab/Simulink simulation of discharging mode - subplots (from top to bottom): cells voltages behavior, cells currents behavior, MOSFETs currents behavior. 
The third subplot depicts the MOSFETs currents, which are the ones bypassed to the cells. It represents the equalization process behavior. As it can be seen, the MOSFETs that are in parallel to the lower voltage cells bypass zero current since all of the current is injected into the corresponding cells, and the effect of the small deviation of one of them is shown as the MOSFET bypasses the intermediate level of current. This intermediate level is mainly enough to bring the cell to its balanced state, which allows the system to decrease the energy losses. The remaining cell (the one that started with a higher voltage than the average one, that is to say, with a higher SOC) is fully bypassed at the beginning, and therefore it can be seen that all of the current goes through its corresponding MOSFET. Then, the cell is being balanced more and more, thus, the MOSFET is bypassing less and less current. When the intermediate level is reached, the MOSFET starts to bypass a constant current until the cell is considered balanced, and then the MOSFET is set to its off-state and the cell is injected with all of the current.

Once it has been checked that the different cells in a string can be balanced, Fig.9 shows the lost energy as a function of the time. It has to be reminded that the different cells SOCs are set in order to simulate a huge unbalance (from $50 \%$ of SOC the least charged cell to $70 \%$ the most charged one). After a charging process of the cells (taking into account that the minimum considered SOC was $50 \%$ ), it can be checked that at the beginning, the amount of losses is high since there is a big unbalance and the equalizer has to work hard, but at the end it can be seen that the relation of lost energy in the equalization process over the total energy delivered by the battery to the charger is really low and is $10 \%$.

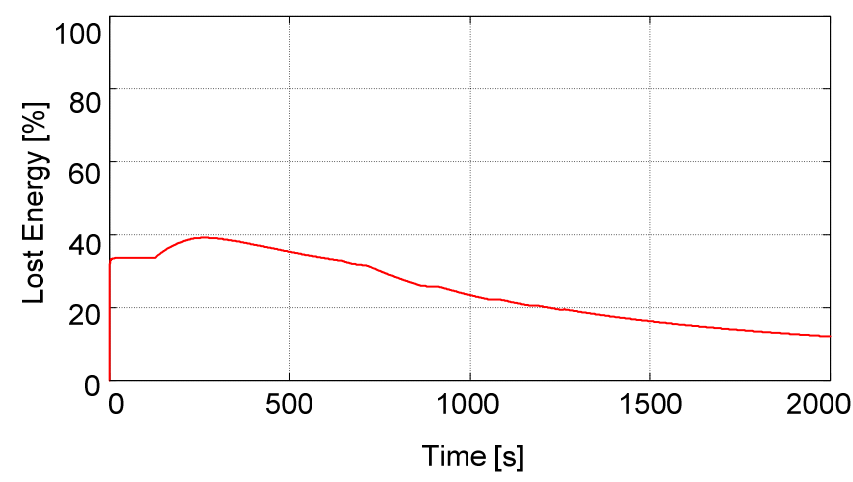

Fig.9. Relation of lost energy over total energy delivered by the battery (\%).

\section{CONCLUSIONS}

Battery system equalizer is a very important issue in an application design which includes energy storage. A well balanced battery system can mainly increase its life, its safety, and optimize the capacity of the battery. The equalizer system has to be able to carry out a proper balance minimizing the lost energy during its operation, obtaining the proposed aim in the shortest possible time, and minimizing its complexity and cost.

In this paper, based on the shunting transistor equalization topology, a novel control is presented, in which all the aforementioned requirements can be satisfied. This simple topology and novel control allow lower losses and low cost equalization, obtaining good results in a really short time. This equalization can be carried out in the battery charging process, which allows the battery system to be balanced, and therefore all the cells in the series string are working under the same conditions along the whole battery life.

\section{ACKNOWLEDGEMENT}

This research was supported by "Ministerio de Economía y Competitividad", "Fondos FEDER", "Junta de Extremadura", "Consejería de Empleo, Empresa e Innovación" and "Fondo Social Europeo".

\section{REFERENCES}

[1] Sveum, P.; Kizilel, R.; Khader, M.; Al-Hallaj, S.; "IIT Plug-in Conversion Project with the City of Chicago", Vehicle Power and Propulsion Conference 2007. VPPC 2007. IEEE, pp.493-497, 9-12 Sept. 2007.

[2] Uno, M.; Tanaka, K.; "Influence of High-Frequency Charge-Discharge Cycling Induced by Cell Voltage Equalizers on the Life Performance of Lithium-Ion Cells", IEEE Transactions on Vehicular Technology, vol.60, no.4, pp.1505-1515, May 2011

[3] Kuhn, B.T.; Pitel, G.E.; Krein, P.T.; "Electrical properties and equalization of lithium-ion cells in automotive applications", IEEE Vehicle Power and Propulsion Conference, 2005, pp. 5, 7-9 Sept. 2005.

[4] Broussely, M.; Perelle, M.; McDowall, J.; Sarre, G.; Martaeng, J; "Lithium ion: the next generation of long life batteries characteristics, life predictions, and integration into telecommunication systems", Telecommunications Energy Conference, 2000. INTELEC. Twentysecond International, pp.194-201, 2000.

[5] Gottwald, T.; Ye, Z.; Stuart, T.; "Equalization of EV and HEV batteries with a ramp converter", IEEE Transactions on Aerospace and Electronic Systems, vol.33, no.1, pp.307-312, Jan. 1997.

[6] Kutkut, N.H.; Wiegman, H.L.N.; Divan, D.M.; Novotny, D.W.; "Design considerations for charge equalization of an electric vehicle battery system", IEEE Transactions on Industry Applications, vol.35, no.1, pp.28-35, Jan/Feb 1999.

[7] Hung, S.T.; Hopkins, D.C.; Mosling, C.R.; "Extension of battery life via charge equalization control", IEEE Transactions on Industrial Electronics, vol.40, no.1, pp.96-104, Feb 1993.

[8] Krein, P.T.; Balog, R.S.; "Life extension through charge equalization of lead-acid batteries", Telecommunications Energy Conference, 2002. INTELEC. 24th Annual International, pp. 516- 523, 2002.

[9] Hopkins, D.C.; Mosling, C.R.; Hung, S.T.; "Dynamic equalization during charging of serial energy storage elements", IEEE Transactions on Industry Applications, vol.29, no.2, pp.363-368, Mar/Apr 1993.

[10] Bentley, W.F.; "Cell balancing considerations for lithium-ion battery systems", Battery Conference on Applications and Advances, 1997., Twelfth Annual, pp.223-226, 14-17 Jan 1997.

[11] Jian Cao; Schofield, N.; Emadi, A.; "Battery balancing methods: A comprehensive review", Vehicle Power and Propulsion Conference, 2008. VPPC '08 IEEE, vol., no., pp.1-6, 3-5 Sept. 2008.

[12] Daowd, M.; Omar, N.; Van Den Bossche, P.; Van Mierlo, J.; "Passive and active battery balancing comparison based on MATLAB simulation" IEEE Vehicle Power and Propulsion Conference (VPPC) 2011, pp.1-7, 6-9 Sept. 2011

[13] Kong Zhi-Guo; Zhu Chun-Bo; Lu Ren-Gui; Cheng Shu-Kang; "Comparison and Evaluation of Charge Equalization Technique for Series Connected Batteries", 37th IEEE Power Electronics Specialists Conference, 2006. PESC '06, pp.1-6, 18-22 June 2006.

[14] Gallardo-Lozano, J.; Milanes-Montero, M.I.; Guerrero-Martinez, M.A.; Romero-Cadaval, E.; "Three-phase bidirectional battery charger for smart electric vehicles", 7th International Conference-Workshop Compatibility and Power Electronics (CPE) 2011, pp.371-376, 1-3 June 2011.

[15] Gallardo Lozano, J; Milanés Montero, María Isabel; Guerrero Martínez, Miguel A.; Romero Cadaval, Enrique; "Electric Vehicle Battery Charger for Smart Grids". Electric Power Systems Research. Vol. 90, pp. 18-29, ISSN 0378-7796. Elsevier. Septiembre 2012. 


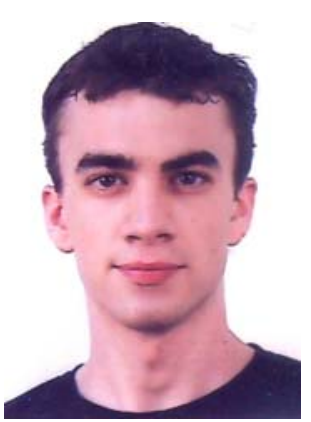

Javier Gallardo-Lozano was born in Badajoz, Spain, in 1968. He received the B.Sc. and the M.Sc. degrees electronic engineering from University of Extremadura, Spain, in 2007 and 2009, respectively, where he is currently working toward the Ph.D. degree. His Ph.D. thesis is devoted to the research and development of energy storage in electric vehicle applications. He is currently with the Power Electrical and Electronic Systems (PE\&ES) Research Group (http://peandes.unex.es). His research interests are power electronics in the power system, battery chargers, battery equalization and electric vehicles.

Postal address: Universidad de Extremadura, Campus universitario, Escuela de Ingenierías Industriales, Laboratorio C2.7, Avda. de Elvas, s/n 06006, Badajoz, Spain.

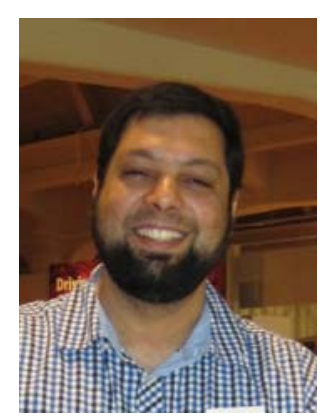

Abdul Lateef received his B.E. (Elec. \& Instr.) from Gulbarga University in 2000 and his M.S.E.E. from Illinois Institute of Technology (IIT) in 2003. From 2004 to 2008, he worked at IIT on safety and thermal management of lithium ion battery systems for high power and high energy applications. From 2008 to 2011, he worked at Technovalutions, Dubai on feasibility of lithium ion batteries for PV applications.

Since 2012 he has been pursuing his graduate studies at the Department of Electrical \& Computer Engineering, McMaster University. His main research area is power conversion and battery safety.

Postal address: 1280 Main Street West, ITB - A102, Hamilton, Ontario, Canada L8S 4K1.

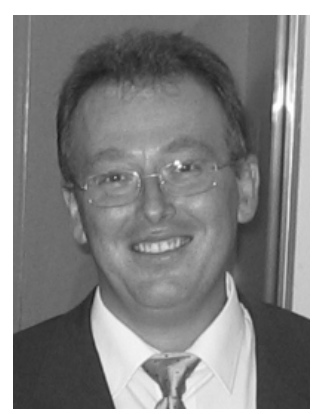

Enrique Romero-Cadaval was born in Villafranca de los Barros, Badajoz, Spain, in 1968. He received the M.Sc. degree in electronic industrial engineering from ICAI, Universidad Pontificia de Comillas, Madrid, Spain, in 1992 and the $\mathrm{Ph}$. D. degree from the Universidad de Extremadura, Badajoz, Spain, in 2004. He is a full Professor in power electronics at the University of Extremadura, Badajoz, Spain. $\mathrm{He}$ is currently with the Power Electrical and Electronic Systems (PE\&ES) Research Group (http://peandes.unex.es). His research interests are power electronics in the power system, power quality, electromagnetic interferences, active power filters, electric vehicle and renewable energy sources control.

Postal address: Universidad de Extremadura, Campus universitario, Escuela de Ingenierías Industriales, Laboratorio C2.7, Avda. de Elvas, s/n 06006, Badajoz, Spain.

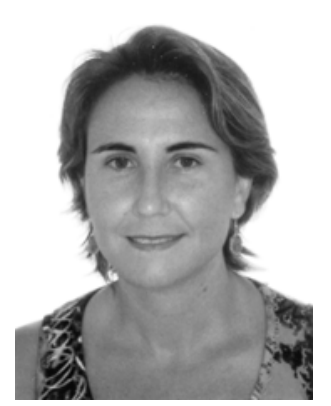

María Isabel Milanés-Montero (S'03M’06) was born in Badajoz, Spain, in 1974. She received the M.Sc. degree in industrial engineering and the Ph.D. degree from the University of Extremadura, Badajoz, in 1997 and 2005, respectively. Since November 1998, she has been with the University of Extremadura, where she was first an Assistant Professor at the Electrical, Electronics and Automation Engineering Department and is currently at the Power Electrical and Electronic Systems Research Group, School of Industrial Engineering. Her major fields of research interest include solid-state power converter design and control, electromagnetic interferences, power quality, renewable energy sources control, and electrical machine drives.

Postal address: Universidad de Extremadura, Campus universitario, Escuela de Ingenierías Industriales, Laboratorio C2.7, Avda. de Elvas, s/n 06006, Badajoz, Spain. 